\title{
Interleukin-6 Facilitates Lipopolysaccharide-Induced Disruption in Working Memory and Expression of Other Proinflammatory Cytokines in Hippocampal Neuronal Cell Layers
}

\author{
Nathan L. Sparkman, ${ }^{1}$ Jessica B. Buchanan, ${ }^{1,2}$ Jonathan R. R. Heyen, ${ }^{1}$ Jing Chen, ${ }^{1}$ James L. Beverly, ${ }^{1,2}$ and \\ Rodney W. Johnson ${ }^{1,2}$ \\ ${ }^{1}$ Laboratory of Integrative Immunology and Behavior, Department of Animal Sciences, and ${ }^{2}$ Division of Nutritional Sciences, University of Illinois, Urbana, \\ Illinois 61801
}

\begin{abstract}
Proinflammatory cytokines inhibit learning and memory but the significance of interleukin-6 (IL-6) in acute cognitive deficits induced by the peripheral innate immune system is not known. To examine the functional role of IL-6 in hippocampus-mediated cognitive impairments associated with peripheral infections, C57BL6/J $\left(\mathrm{IL}^{-6^{+/+}}\right)$and IL- 6 knock-out (IL-6 $\left.{ }^{-/-}\right)$mice were trained in a matching-to-place version of the water maze. After an acquisition phase, $\mathrm{IL}-6^{+/+}$mice injected intraperitoneally with lipopolysaccharide (LPS) exhibited deficits in working memory. However, IL- $6^{-1-}$ mice were refractory to the LPS-induced impairment in working memory. To determine the mechanism by which IL- 6 deficiency conferred protection from disruption in working memory, plasma IL- $1 \beta$ and tumor necrosis factor $\alpha$ (TNF $\alpha$ ), c-Fos immunoreactivity in the nucleus of the solitary tract (NTS), and steady-state levels of IL-1 $\beta$ and TNF $\alpha$ mRNA in neuronal layers of the hippocampus were determined in IL- $6^{+/+}$and IL- $6^{-/-}$mice after injection of LPS. Plasma IL- $1 \beta$ and TNF $\alpha$ and c-Fos immunoreactivity in the NTS were increased similarly in IL-6 $6^{+/+}$and IL-6 ${ }^{-1-}$ mice after LPS, indicating high circulating levels of IL- $1 \beta$ and TNF $\alpha$ and activation of vagal afferent pathways were not sufficient to disrupt working memory in the absence of IL-6. However, the LPS-induced upregulation of IL- $1 \beta$ and TNF $\alpha$ mRNA that was evident in hippocampal tissue of IL- $6^{+/+}$mice was greatly attenuated or entirely absent in IL- $6^{-1-}$ mice. Collectively, these data suggest that humoral and neural immune-to-brain communication pathways are intact in IL-6-deficient mice but that, in the absence of IL-6, the central cytokine compartment is hyporesponsive.
\end{abstract}

Key words: interleukin-6; lipopolysaccharide; cytokines; working memory; hippocampus; mice

\section{Introduction}

Infection in the periphery stimulates immune cells to produce inflammatory cytokines such as interleukin- $1 \beta$ (IL-1 $\beta$ ), IL-6, and tumor necrosis factor $\alpha$ (TNF $\alpha)$. These cytokines activate neural and humoral communication pathways that induce glial cells in discrete brain regions to produce the same inflammatory cytokines (Buttini and Boddeke, 1995; Quan et al., 1998; Maier et al., 1998; Rivest, 2003). Within the CNS, cytokines provide a sensory representation of the conditions in the periphery (Blalock, 1994) and induce neurochemical changes that elicit an adaptive behavioral response (Pugh et al., 1998; Konsman et al., 2002; Kelley et al., 2003; Dantzer, 2004). Unfortunately, the ben-

Received Jan. 9, 2006; revised Aug. 4, 2006; accepted Aug. 30, 2006.

This work was supported by National Institutes of Health Grants AG16710, AG023580, and MH069148 (R.W.J.). J.B.B. was supported by National Institutes of Health Ruth L. Kirchenstein National Research Service Award (T32 DK59802). We thank Dr. James F. Zachary (Department of Pathobiology, College of Veterinary Medicine, University of Illinois Urbana-Champaign, Urbana, IL) for his assistance with the laser capture microdissection.

Correspondence should be addressed to Rodney W. Johnson, Laboratory of Integrative Immunology and Behavior, Department of Animal Sciences, University of Illinois Urbana-Champaign, 1207 West Gregory Drive, Urbana, IL 61801. E-mail: rwjohn@uiuc.edu.

DOI:10.1523/JNEUROSCI.3376-06.2006

Copyright $\odot 2006$ Society for Neuroscience $\quad$ 0270-6474/06/2610709-08\$15.00/0 eficial behavioral response is sometimes accompanied by an insidious decline in cognition. For example, acute cognitive impairment in the elderly often associated with a peripheral infection (Wofford et al., 1996), results in a failure of self-care and is associated with increased hospitalization and delayed recovery (Johnston et al., 1987).

Inflammatory cytokine receptors are highly concentrated in areas associated with learning and memory, including regions of the hippocampus (Takao et al., 1992; Gadient and Otten, 1994; Haour et al., 1998; Loddick et al., 1998; Parnet et al., 2002). Furthermore, inflammatory cytokines inhibit long-term potentiation (LTP) (Tancredi et al., 2000; Vereker et al., 2000; Curran and O'Connor, 2003; Butler et al., 2004; Pickering et al., 2005) and induce performance deficits in hippocampal-mediated cognitive tests (Pugh et al., 1998, 2001; Arai et al., 2001; Shaw et al., 2001; Barrientos et al., 2002, 2006; Yirmiya et al., 2002; Sparkman et al., $2005 a, b)$. Inflammatory cytokines are upregulated in the hippocampus during peripheral immune activation and have overlapping and synergistic neurobehavioral effects that have made it difficult to elucidate their individual roles (Buttini and Boddeke, 1995; Quan et al., 1998; Schneider et al., 1998; Brebner et al., 2000; Hansen et al., 2000; Berg et al., 2005). However, recent 
studies suggest IL- 6 may sit in a pivotal position and serve as an important catalyst because administration of IL- 6 neutralizing antibodies prolonged LTP and improved spatial alternation behavior (Balschun et al., 2004) and facilitated recovery from lipopolysaccharide (LPS)-induced sickness behavior (Bluthé et al., 2000). Furthermore, circulating IL-6 is positively correlated with deficits in cognition in humans (Weaver et al., 2002).

Therefore, in the current study to examine the role of IL-6 in acute cognitive disturbances associated with peripheral infections, we established a matching-to-place version of the water maze and determined a critical time point when animals suffered disturbances in spatial working memory after LPS administration. Using this model, we then examined the effects of LPS on spatial working memory in both IL- $6^{+/+}$and IL- $6^{-/-}$mice and determined the effects of IL- 6 deficiency on the ability of the peripheral immune system to convey a message to the brain and induce inflammatory cytokine expression in the neuronal cell layers of the hippocampus. The results indicate that IL- $6^{-1-}$ mice are resistant to LPS-induced deficits in spatial working memory probably because cytokine-producing cells in the hippocampus are unresponsive to signals emerging from the peripheral immune system.

\section{Materials and Methods}

Animals and treatments. Three-month-old male wild-type C57BL/6 (IL$6^{+/+}$) and IL-6 knock-out (IL-6 ${ }^{-/-}$) (B6.129S2-Il6tm1 ${ }^{\text {Kopf/J }}$ ) (Kopf et al., 1994) mice were purchased from The Jackson Laboratory (Bar Harbor, ME). On arrival, mice were paired by genotype and housed under a $12 \mathrm{~h}$ reverse light/dark cycle at $22^{\circ} \mathrm{C}$ with ad libitum access to food and water. Mice were allowed at least $14 \mathrm{~d}$ to acclimate before experiments were initiated. All animals were $3-5$ months of age at the time of testing. Experiments were conducted during the dark phase of the light/dark cycle, and when appropriate, mice were injected intraperitoneally with sterile saline or $100 \mu \mathrm{g}$ of Escherichia coli LPS (serotype 0127:B8; Sigma, St. Louis, MO). All procedures were in accordance with the National Institutes of Health Guidelines for the Care and Use of Laboratory Animals and were approved by the University of Illinois Institutional Animal Care and Use Committee.

Spatial working memory. To evaluate hippocampus-dependent spatial working memory, a modified Morris water maze was used (Morris, 1984). A circular tank, $1.8 \mathrm{~m}$ in diameter and $0.6 \mathrm{~m}$ deep, painted white, and filled with water $\left(24-26^{\circ} \mathrm{C}\right)$ to a depth of $0.25 \mathrm{~m}$, was used. A transparent round platform, $4 \mathrm{~cm}$ in diameter, was constructed from Plexiglas and positioned $\sim 0.5 \mathrm{~cm}$ below the surface of the water. The nonvisible platform was randomly placed in one of four preset positions for each session of testing. Numerous visual cues were located outside the tank. A video camera mounted to the ceiling directly above the center of the maze was used in conjunction with the HVS VP 200 tracking system (HVS Image; Ormend Cres, Hampton, UK).

For all experiments, training took place during a $7 \mathrm{~d}$ acquisition phase with three massed trials administered each day. In some experiments, a single bolus injection of saline or LPS was administered during the acquisition phase when mice were still learning the relationship between spatial cues to determine treatment effects on spatial memory consolidation. In other experiments, a single bolus injection of saline or LPS was administered after the acquisition phase during a testing phase to determine treatment effects on an animal's ability to integrate new information with existing memories to complete a hippocampus-dependent task.

To begin each trial, a mouse was pseudorandomly placed in the water in one of four preset locations (designated $\mathrm{N}, \mathrm{S}, \mathrm{E}, \mathrm{W}$ ) $\sim 2 \mathrm{~cm}$ from the edge of the tank facing the wall. Mice were allowed to swim freely a maximum of $120 \mathrm{~s}$ or until the platform was located. After the mouse reached the platform, it was required to remain there for $30 \mathrm{~s}$. After completion of three consecutive trials, mice were placed in a cage under a heat lamp for $\sim 10 \mathrm{~min}$, and then returned to their home cage. If the platform was not located during the $120 \mathrm{~s}$, mice were guided to the platform and allowed to remain there for $30 \mathrm{~s}$. Because location of the platform was changed with every new session of trials, mice were placed on the platform for $30 \mathrm{~s}$ preceding the start of each session of testing. Performance parameters that were determined included swim speed, latency to the platform, and distance swam.

Inflammatory cytokines in plasma and hippocampus. In a separate study, mice were killed $4 \mathrm{~h}$ after injection of saline or LPS by $\mathrm{CO}_{2}$ asphyxiation, and blood samples were collected into EDTA-coated syringes via cardiac puncture and centrifuged at $2000 \times g$ for $20 \mathrm{~min}\left(4^{\circ} \mathrm{C}\right)$. Plasma was collected and stored at $-80^{\circ} \mathrm{C}$ until assaying for cytokines. Plasma samples were assayed for IL- $1 \beta$, TNF $\alpha$, IL- 6 , and the anti-inflammatory cytokine IL-10, using multiplexed bead-based immunoassay kits combined with a Cytokine Reagent kit as described by the manufacturer (Bio-Rad, Hercules, CA). The multiplex assay was sensitive to $<2 \mathrm{pg} / \mathrm{ml}$ IL- $1 \beta$, TNF $\alpha$, IL- 10 , and $<8 \mathrm{pg} / \mathrm{ml}$ IL- 6 ; the interassay and intra-assay coefficients of variation were $<8 \%$.

After blood sampling, brains were removed, trimmed, and embedded in OCT, chilled on dry ice, and stored at $-80^{\circ} \mathrm{C}$ until sectioning. Eightmicrometer-thick sections were cut at $-20^{\circ} \mathrm{C}$ to prevent RNA degradation using a Leica (Nussloch, Germany) Cryocut 1800. Coronal sections containing the hippocampal formation $(-2.18 \mathrm{~mm}$ from the bregma) were mounted on SuperFrost Plus slides and immediately placed on dry ice and stored at $-80^{\circ} \mathrm{C}$. Frozen sections were thawed at room temperature for $30 \mathrm{~s}$ and fixed for $30 \mathrm{~s}$ in $75 \%$ ethanol. After fixation, sections were rehydrated in RNase-free water for $20 \mathrm{~s}$ and stained with $1 \% \mathrm{cresyl}$ violet for $20 \mathrm{~s}$ to reveal hippocampal neuronal layers. Sections were rinsed with RNase-free water for $20 \mathrm{~s}$ and dehydrated in a series of ethanol baths (30 s in 70\% ethanol; $30 \mathrm{~s}$ in $90 \%$ ethanol; and $1 \mathrm{~min}$ in $100 \%$ ethanol). Finally, sections were incubated in xylene for $5 \mathrm{~min}$ and air dried for $5 \mathrm{~min}$. Laser capture microdissection (LCM) was performed using an Arcturus PixCell IIe laser capture microscope and Arcturus version 2.0.0 software (Arcturus Engineering, Mountain View, CA). A laser spot size of $15 \mu \mathrm{m}$ was used with a power setting of $35 \mathrm{~mW}$ and pulse duration of $6 \mathrm{~ms}$. The dentate gyrus (DG) and cornu ammonis (CA) regions captured from four to six adjacent sections within each subject were pooled and immediately lysed in $10 \mu \mathrm{l}$ of extraction buffer provided in an Arcturus PicoPure RNA isolation kit. RNA lysates were stored at $-80^{\circ} \mathrm{C}$, and later, total RNA was isolated from hippocampal tissue using the Arcturus PicoPure RNA isolation kit as described by the manufacturer. DNase treatment was performed on a PicoPure column with a Qiagen (Hilden, Germany) RNase-free DNase set. Total RNA was measured using the Ambion (Austin, TX) NanoDrop ND-1000A UV-Vis spectrophotometer, which showed each sample yielded $4-6 \mathrm{ng} / \mu \mathrm{l}$. RNA was reverse transcribed using the Sensiscript RT kit (Qiagen, Valencia, CA). In brief, $10 \mu$ l of sample RNA were added to RT master mix, which included random 9-mers (10 $\mu \mathrm{M}$; Operon, Alameda, CA), dNTP (5 mM each), RNase inhibitor (10 U; Rnasin; Promega, Madison, WI), $1 \mu \mathrm{l}$ Sensiscript $20 \mathrm{X}$ and $2 \mu \mathrm{l}$ of $10 \times$ reaction buffer to reach a final volume of $20 \mu \mathrm{l}$. The RT mix was incubated at $37^{\circ} \mathrm{C}$ for $60 \mathrm{~min}$ and the cDNA was stored at $-20^{\circ} \mathrm{C}$.

Quantitative PCR was performed using the Applied Biosystems (Foster, CA) Assay-on Demand Gene Expression protocol as we have done previously (Berg et al., 2005). cDNA was amplified by PCR, where a target cDNA (IL-6, Mm00446190_m1; IL-1 $\beta$, Mm00434228_m1; TNF $\alpha$, Mm00443258_m1) and a reference cDNA (glucose-3 phosphate dehydrogenase, Mm99999915_g1) were amplified simultaneously using an oligonucleotide probe with a $5^{\prime}$ fluorescent reporter dye [6-FAM (6carboxyfluorescein)] and a $3^{\prime}$ quencher dye [NFQ (nonfluorescent quencher)]. PCRs were performed at the following conditions: $50^{\circ} \mathrm{C}$ for 2 $\min , 95^{\circ} \mathrm{C}$ for $10 \mathrm{~min}$, followed by 40 cycles of $95^{\circ} \mathrm{C}$ for $15 \mathrm{~s}$ and $60^{\circ} \mathrm{C}$ for 1 min. Fluorescence was determined on an ABI PRISM 7900HTsequence detection system (PerkinElmer, Forest City, CA). Data were analyzed using the comparative threshold cycle $(\mathrm{Ct})$ method, and results are expressed as fold difference.

Immunohistochemical staining and quantification. Four hours after intraperitoneal injection of saline or LPS, mice were killed by $\mathrm{CO}_{2}$ asphyxiation and transcardially perfused with heparinized saline followed by $4 \%$ paraformaldehyde, and the brains were removed. Brains were blocked in three parts (rostral, mid, and caudal), postfixed over $2 \mathrm{~d}$ in $4 \%$ paraformaldehyde, and then paraffin embedded. Sections $(4 \mu \mathrm{m}$ at the 
level of the area postrema) were cut on a microtome and every 10th section was stained for c-Fos [c-Fos (4) sc-52; Santa Cruz Biotechnology, Santa Cruz, CA]. Sections were dewaxed and rehydrated through xylene and alcohols and were incubated in citrate buffer, $\mathrm{pH}$ 6, and microwaved for $10 \mathrm{~min}$. Endogenous peroxidase was eliminated by incubating sections in $3 \% \mathrm{H}_{2} \mathrm{O}_{2} /$ methanol for $15 \mathrm{~min}$. Sections were washed in PBS and blocked with $20 \%$ normal goat serum before overnight incubation at $4{ }^{\circ} \mathrm{C}$ with the primary antibody at 1:800 dilution in 5\% blocking serum. The sections were washed, and then incubated with biotinylated goat antirabbit antibody (Vector Laboratories, Burlingame, CA) for $1 \mathrm{~h}$. Staining was visualized using the $\mathrm{ABC}$ method and nickel-enhanced 3,3'diaminobenzidine as chromagen. Isotype-matched IgG was used as a negative control. Immunostaining was visualized using an Optronix (Goleta, CA) Microfire camera (model S99808) attached to a Zeiss (Gottingen Germany) Axio Imager A.1 microscope. The number of c-Fospositive cells in the nucleus of the solitary tract (NTS) was determined using Image (version 1.36b; http://rsb.info.nih.gov/ij/). The number of c-Fos-positive cells was determined in both hemispheres of a given section, and a total of four sections was analyzed per mouse.

Statistical analysis. Means for each session were calculated, and behavioral data were subjected to repeated-measures ANOVA as a two-way design, in which test day was a within-subjects measure (i.e., repeated measure), and LPS (saline or $100 \mu \mathrm{g}$ ) and genotype (IL- $6^{+/+}$or IL$6^{-1-}$ ) were between-subjects measures. Plasma cytokine levels, cytokine mRNA levels in hippocampal tissue, and c-Fos-positive cells in NTS were analyzed using separate two-way ANOVAs in which LPS and genotype were dependent variables. When the ANOVAs revealed a significant effect of main factors or main factor interactions, differences in treatment group means were tested using Fisher's least-significant differences. All data are presented as means \pm SEM.

\section{Results}

Performance in the matching-to-place version of the water maze

To standardize a matching-to-place protocol, IL- $6^{+/+}(n=7)$ mice were subjected to seven training sessions (days) that included three massed trials each day (i.e., acquisition phase). The parameters analyzed included latency to the platform, distance swam, and swim speed. Changes in performance parameters were observed over the course of the experiment, as a main effect of training session was evident for latency, speed, and distance swam $(p<0.01)$ (data not shown). Both latency and distance swam decreased over the course of the experiment but reached an asymptotic level by the fourth training session (day 4). These changes likely coincided with mice abandoning random searching patterns and using the visual cues provided. These data indicate that IL- $6^{+/+}$mice learn and excel in the matching-to-place version of the water maze.

Acute cognitive disorders are common in patients with a peripheral infection and can complicate disease diagnosis and treatment. However, the possibility that activation of the peripheral innate immune system affects hippocampal-dependent spatial working memory has not been investigated fully. Therefore, in an initial study, the effect of peripheral LPS on acquisition of spatial learning in a matching-to-place task was investigated. IL- $6^{+/+}$ mice received either a single intraperitoneal injection of LPS or saline $4 \mathrm{~h}$ before training on day 3 when they were still learning the relationship between spatial cues (i.e., during acquisition; $n=$ 12). Repeated-measures ANOVA revealed significant main effects of day $(p<0.01)$, LPS $(p<0.01)$ and a significant day by LPS interaction $(p<0.01)$ for latency to reach the platform (Fig. $1)$. Animals receiving LPS took longer to complete the task. However, LPS did not affect the distance swam to escape (Fig. 1), suggesting that it slowed time to platform by reducing swim speed and not by disrupting memory during acquisition.

In a subsequent study, LPS was administered after the acqui-

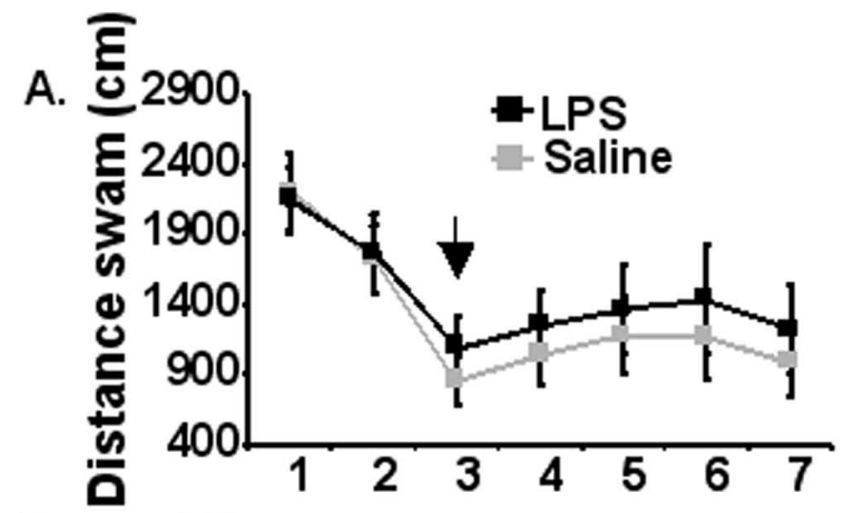

B.
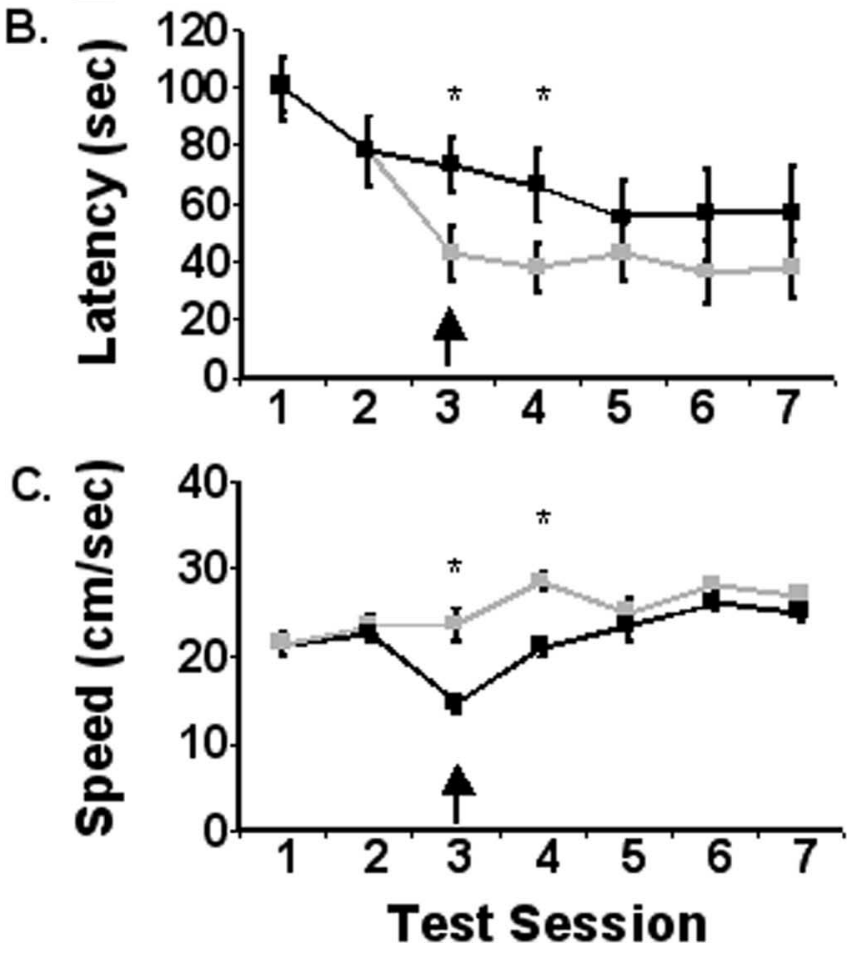

Figure 1. Matching-to-place performance for IL-6 ${ }^{+/+}$mice that received LPS (black line) or saline (gray line) $4 \mathrm{~h}$ before test session 3. $\boldsymbol{A}$, Distance swam to platform across testing days. $\boldsymbol{B}$, Latency to find the platform across testing days. $\boldsymbol{C}$, Swim speed. Data are presented as mean \pm SEM. The arrow designates day of treatment. *Significant difference between groups as determined by Fisher's protected least-significant difference ( $p<0.05$ ).

sition phase to determine whether activation of the peripheral innate immune system interfered with an animal's ability to integrate new information with existing memories to complete a hippocampus-dependent task. Mice were subjected to a $7 \mathrm{~d}$ acquisition period and effects of LPS on spatial working memory in a matching-to-place task were assessed during a $5 \mathrm{~d}$ testing period that immediately followed. After the acquisition phase and before training on test day 2 (day 9), IL- $6^{+/+}$mice were injected intraperitoneally with saline or LPS and swam $4 \mathrm{~h}$ later and every $24 \mathrm{~h}$ thereafter $(n=12)$. Repeated-measures ANOVA of swim speed, escape latency, and distance swam during the $5 \mathrm{~d}$ testing period (days 8-12) revealed significant main effects of day, LPS and day by LPS interactions for each performance measures $(p<0.01)$. Mice treated with LPS swam slower and had increased escape latencies the day of treatment (day 9) and $24 \mathrm{~h}$ later (day 10) compared with saline controls $(p<0.01)$ (Fig. 2). Furthermore, LPS-treated mice had increased distance swam to platform on day 9 compared with saline controls $(p<0.01)$ (Fig. 2). These 

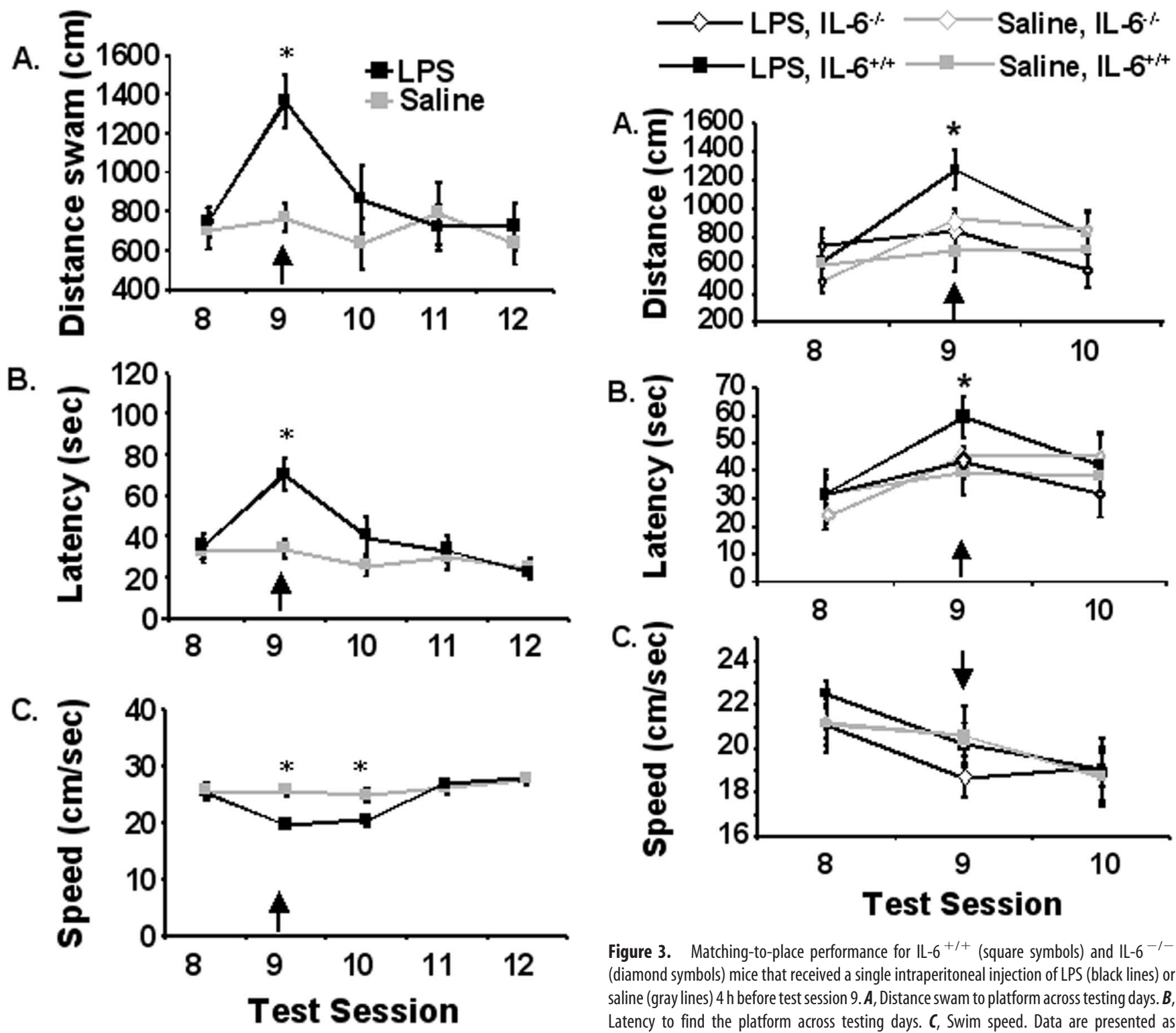

Figure 3. Matching-to-place performance for IL- $6^{+/+}$(square symbols) and IL-6 ${ }^{-/-}$ (diamond symbols) mice that received a single intraperitoneal injection of LPS (black lines) or saline (gray lines) $4 \mathrm{~h}$ before test session 9. $\boldsymbol{A}$, Distance swam to platform across testing days. $\boldsymbol{B}$, Latency to find the platform across testing days. $C$, Swim speed. Data are presented as mean \pm SEM. The arrow designates day of treatment. *Significant difference between groups as determined by Fisher's protected least-significant difference $(p<0.05)$.

Figure 2. Matching-to-place performance for IL- $6^{+/+}$mice that received a single intraperitoneal injection of LPS (100 $\mu \mathrm{g}$; black line) or saline (gray line) $4 \mathrm{~h}$ before test session 9. $A$, Distance swam to platform across testing days. $\boldsymbol{B}$, Latency to find the platform across testing days. $C$, Swim speed. Data are presented as mean \pm SEM. * Significant difference between groups as determined by Fisher's protected least-significant difference $(p<0.05)$.

findings showed that LPS administration after the acquisition phase impaired the ability of mice to locate the platform in a matching-to-place version of the Morris water maze. Collectively, results from the two studies suggest that activation of the peripheral innate immune system did not inhibit acquisition during the early phase of testing but reduced the ability to affectively integrate new information with existing memories to complete this hippocampus-dependent task at the later time point.

IL-6 ${ }^{-1-}$ mice are refractory to LPS-induced deficits in spatial working memory

Studies suggest that IL-6 may serve as an important facilitator of proinflammatory cytokine-induced behavioral changes (Bluthé et al., 2000). Therefore, the purpose of this study was to examine the role of IL- 6 in LPS-induced decrements in working memory. IL- $6^{+/+}$and IL- $6^{-1-}$ mice were subjected to a $7 \mathrm{~d}$ acquisition

period, and effects of LPS on spatial working memory in a matching-to-place task were assessed during a $3 \mathrm{~d}$ testing period. After the acquisition phase and before training on test day 2 (day $9)$, mice were injected intraperitoneally with saline or LPS and swam $4 \mathrm{~h}$ later and every $24 \mathrm{~h}$ thereafter $(n=8-10)$. Genotype did not influence performance in the matching-to-place water maze task during the $7 \mathrm{~d}$ acquisition phase (data not shown). However, during the testing phase (days 8-10), a significant day by genotype by LPS interaction for distance swam to reach the platform was observed $(p<0.05)$. On day 9 after injection, IL$6^{+/+}$mice that received LPS swam further to locate the platform compared with saline-treated IL- $6^{+/+}$mice $(p<0.05)$, salinetreated IL- $6^{-1-}$ mice $(p<0.05)$, and LPS-treated IL- $6^{-1-}$ mice $(p<0.05)$. An ANOVA of day 9 latency data revealed a significant genotype by treatment interaction $(p<0.05)$, in which IL- $6^{+/+}$mice treated with LPS took longer to locate the platform than LPS- or saline-treated IL- $6^{-1-}$ mice or saline-treated IL- $6^{+/+}$mice (Fig. 3). After treatment on day 9, animals receiving LPS tended ( $p=0.08$ ) to swim slower than they did the day 


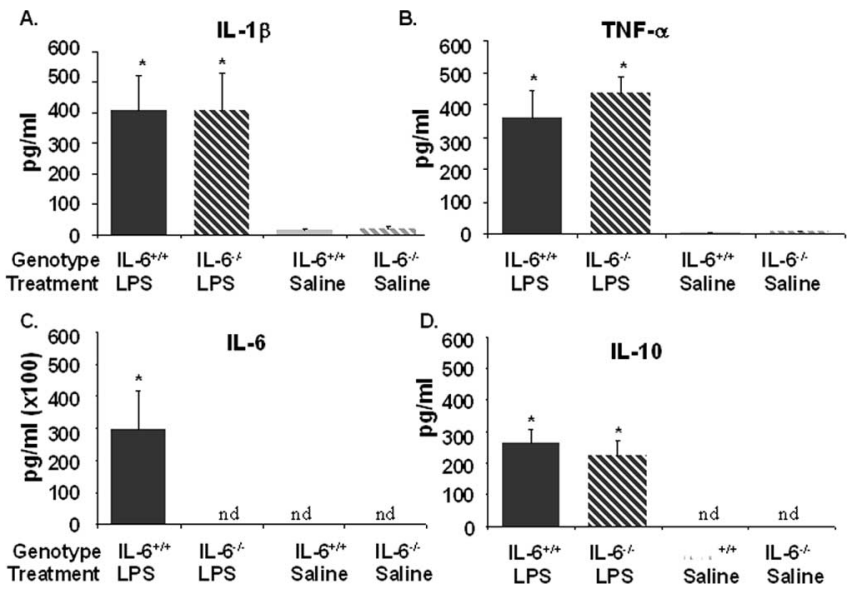

Figure 4. Plasma cytokine levels for IL- $6^{+/+}$(solid filled bars) and IL- $6^{-/-}$(striped bars) mice that received a single intraperitoneal injection of LPS (black-filled bars) or saline (grayfilled bars) $4 \mathrm{~h}$ before kill. $\boldsymbol{A}$, IL-1 $\beta$. $\boldsymbol{B}$, TNF- $\alpha$. C, IL-6. $\boldsymbol{D}$, IL-10. Data are presented as mean \pm SEM. nd, Cytokine levels were nondetectable. ${ }^{*}$ Significant difference between groups as determined by Fisher's protected least-significant difference $(p<0.05)$.

before, regardless of genotype. These findings indicate that mice deficient in IL-6 showed signs of lethargy but were refractory to deficits in spatial working memory caused by LPS. Thus, the ability to effectively integrate new information with existing memories to complete a hippocampus-dependent task may be directly or indirectly inhibited by IL-6.

\section{Deficiency of IL-6 decreases central but not peripheral production of IL-1 $\beta$ and TNF $\alpha$}

When produced by activated cells of the innate immune system, inflammatory cytokines such as IL-1 $\beta$ and TNF $\alpha$ may induce cognitive deficits independent of IL- 6 . Thus, if IL- 6 deficiency resulted in decreased production of IL- $1 \beta$ and TNF $\alpha$, this might explain why IL- $6^{-1-}$ mice are refractory to LPS-induced deficits in spatial working memory. In addition, changes in antiinflammatory cytokines like IL-10 might be involved. Therefore, the effect of IL-6 deficiency on LPS-induced cytokine production was assessed. In an initial study, cytokines were measured in plasma obtained from IL- $6^{+/+}$and IL- $6^{-/-}$mice $4 \mathrm{~h}$ after injection of saline or LPS $(n=8)$. As anticipated, plasma IL- $1 \beta$, TNF $\alpha$, IL-6, and IL-10 concentrations were increased in IL- $6^{+/+}$mice after LPS (Fig. 4). In IL-6 ${ }^{-/-}$mice, although IL-6 in plasma was not detectable before or after LPS, plasma IL- $1 \beta$, TNF $\alpha$, and IL-10 concentrations were increased to the same magnitude as in IL$6^{+/+}$mice after LPS (Fig. 4). Thus, despite being refractory to LPS-induced deficits in spatial working memory, IL- $6^{-1-}$ mice had high circulating levels of IL- $1 \beta$ and TNF $\alpha$.

Finding no effect of IL-6 deficiency on the LPS-induced increase in plasma IL- $1 \beta$ and TNF $\alpha$, we next sought to determine whether IL-6 deficiency affected expression of inflammatory cytokines in the central compartment by measuring steady-state levels of IL- $1 \beta$ and TNF $\alpha$ mRNA in the hippocampus of IL- $6^{+/+}$ and IL- $6^{-1-}$ mice after injection of saline or LPS $(n=8)$. Previous studies have examined inflammatory cytokines in the entire hippocampal formation of wild-type mice after manual dissection, thus combining neurons, glia, and white matter from various regions. To obtain a more homogeneous cell population and to better assess the microenvironment that hippocampal neurons experience when the peripheral innate immune system is activated, LCM was used to separate the neuronal cell layers (i.e., DG and CA regions) from surrounding hippocampal tissue (Fig. 5).
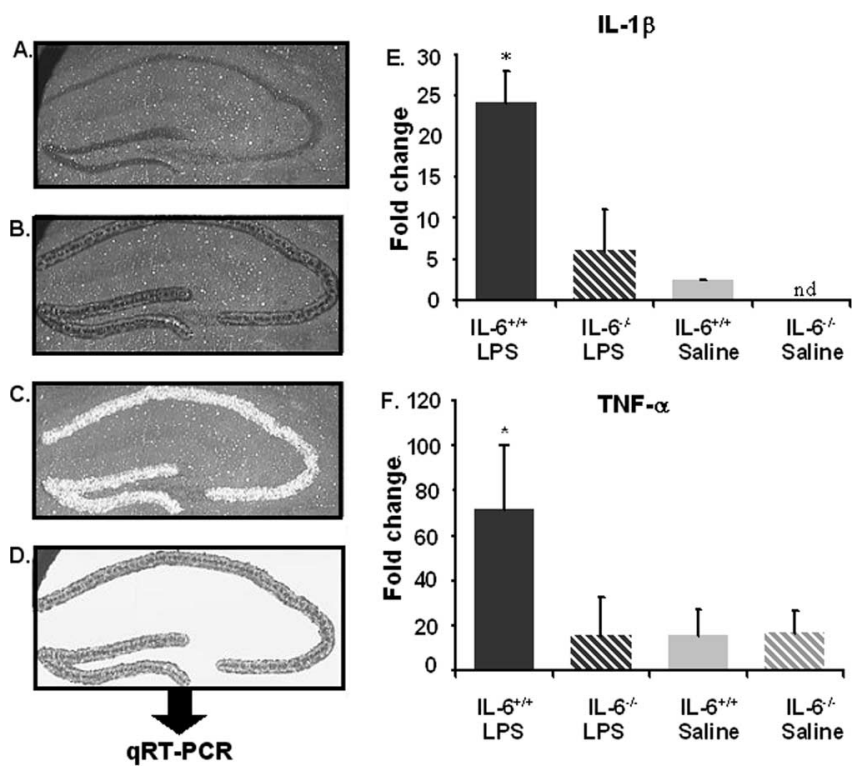

Figure 5. $\boldsymbol{A}-\boldsymbol{D}$, Laser capture microdissection of the hippocampal neuronal layer. $\boldsymbol{A}-\boldsymbol{D}$, Stained section $(\boldsymbol{A})$, captured neuronal layer $(\boldsymbol{B})$, section with removed hippocampus $(\boldsymbol{C})$, and isolated hippocampal neuronal layer (D). $\boldsymbol{E}, \boldsymbol{F}$, Percent fold change for mRNA cytokine levels for IL- $6^{+/+}$(solid filled bars) and IL- $6^{-/-}$(striped bars) mice that received a single intraperitoneal injection of LPS (black-filled bars) or saline (gray-filled bars) $4 \mathrm{~h}$ before kill. IL-1 $\beta$ mRNA (E) and TNF- $\alpha(\boldsymbol{F})$. Data are presented as mean \pm SEM. nd, Cytokine levels were nondetectable. * Significant difference between groups as determined by Fisher's protected least-significant difference $(p<0.05)$.

Cytokine mRNA was subsequently measured in the hippocampal neuronal cell layers by quantitative RT-PCR. As anticipated, LPS increased IL- $1 \beta$ and TNF $\alpha$ mRNA in IL- $6^{+/+}$mice $(p<0.001)$ (Fig. 5). However, in IL- $6^{-1-}$ mice, the LPS-induced increase in IL- $1 \beta$ and TNF $\alpha$ mRNA was ablated (Fig. 5). Thus, these findings showed that IL- 6 deficiency disrupted communication between the peripheral innate immune system and the brain by preventing the LPS-induced upregulation of IL- $1 \beta$ and TNF $\alpha$ mRNA.

\section{LPS-induced c-Fos immunoreactivity in the NTS is not affected by IL-6 deficiency}

Peripheral inflammatory stimuli like LPS or cytokines activate vagal afferent pathways and induce neuronal responses that stimulate the production of cytokines within the brain. Neurons in the NTS are particularly responsive to peripheral LPS. Many of these neurons project to midbrain and forebrain regions that mediate behaviors associated with sickness. Therefore, we determined whether IL-6 deficiency affected activation of the immune-responsive NTS by staining c-Fos, a widely used marker for functional activation. Saline-treated IL- $6^{+/+}$and IL- $6^{-1-}$ mice had little to no c-Fos immunoreactivity in the NTS (Fig. 6). c-Fos immunoreactivity in the NTS was markedly increased in both genotypes after injection of LPS $(p<0.05)$. The effects of LPS on activation of the immune-responsive neurons in the NTS, however, were similar in both $\mathrm{IL}-6^{-/-}$and IL- $6^{+/+}$mice. Collectively, these data indicate that IL- $6^{-1-}$ mice activate traditional immune-to-brain communication pathways when the peripheral innate immune system is stimulated but that, in the absence of IL-6, the central cytokine compartment is hyporesponsive.

\section{Discussion}

In the current study, IL- $6^{+/+}$mice administered LPS after the training phase demonstrated decreased efficiency in locating the 
platform. Furthermore, IL-6 seems to be an important mediator of the LPS-induced cognitive deficits, because IL- $6^{-1-}$ animals were refractory to LPS-induced impairments in spatial working memory. Whereas previous studies demonstrated that LPS can impair memory consolidation (Barrientos et al., 2002) or slow the rate of acquisition across days of testing (Sparkman et al., 2005a,b), the current results showed an acute effect suggestive of impaired cognitive function rather than disruption of memory formation (consolidation). This is evident in the fact that in the later experiments when animals had already acquired the task, IL- $6^{+/+}$mice were less efficient in their navigation of the maze after LPS injection compared with LPS-treated $\mathrm{IL}-6^{-1-}$ mice or salinetreated mice. These results are consistent with hippocampal dysfunction, because the hippocampus seems to be a critical component for forming relational representations and strategic flexibility in the Morris water maze (Squire, 1992). In the current testing paradigm, the relevance of alternative platform positions becomes more salient across test sessions; thus, completing the task during later test sessions requires a greater cognitive load and may be more susceptible to interference than during the early acquisition phase. Previous studies using the standard reference memory version of the Morris water maze have reported that pretreatment before the start of training can exert nonspecific disruptions in efficiency to locate the platform in later test sessions (Shaw et al., 2001; Sparkman et al., 2005b). These types of studies cannot differentiate between deficits in cognition (working memory) and disruptions in memory consolidation, because animals are actively acquiring a new task at the same time of the treatment. LPS has been shown to inhibit memory consolidation in fear conditioning tasks (Pugh et al., 1998) and may also disrupt this process during the acquisition of Morris water maze training. By using later time points for treatment (after the acquisition phase) in the matching-to-place version of the task, we were able to demonstrate that LPS is capable of disrupting cognitive performance independent of generalized effects on memory consolidation. We do not expect that LPS disrupts the retrieval of previously learned information, because LPS has not been shown to disrupt behavior in a previously learned task (Aubert et al., 1995; Sparkman et al., 2005a). We suggest that LPS-treated animals demonstrate an inability to effectively incorporate the new platform position into the old schema. It should be noted, however, that the effects of LPS are likely dependent on dosage and the nature of the cognitive task being investigated. Human subjects given a very low dose of LPS reported no subjective feelings of illness but had decreased performance of tests of declarative memory and increased performance in working memory (Cohen et al., 2003).

Even basal levels of cytokines may effect learning and memory. For example, treatment with an IL-6 neutralizing antibody prolonged LTP and improved spatial alternation in rats (Balschun et al., 2004), and Braida et al. (2004) reported facilitated radial arm maze performance in 4- and 12-month-old IL-6 ${ }^{-1-}$ mice. The results of the latter study (Braida et al., 2004) appear at odds with our results; however, improved performance by 4-month-old IL-6 $6^{-1-}$ mice was not reliably evident until nearly $20 \mathrm{~d}$ of testing, and IL- $6^{-1-}$ animals were more likely to enter an arm adjacent to the one they just left. This tendency was greatly enhanced in older IL- $6^{-1-}$. Therefore, the extent to which the animals show a facilitation of hippocampal-dependent spatial working memory is difficult to interpret, because IL- $6^{-1-}$ mice were more likely to use a simple serial search strategy. In our study, IL-6 ${ }^{-1-}$ mice did not differ from controls in their baseline levels of performance (i.e., acquisition) in the matching-to-place version of the water maze. Furthermore, as hypothesized, only after treatment with LPS was a difference apparent between control and knock-out animals. Together, these results demonstrate that, in the brain, cytokines have important normative functions in learning and memory and that perturbation of steady-state levels may alter cognitive processes.

Circulating proinflammatory cytokines are often increased in patients experiencing cognitive decline (Reichenberg et al., 2001; Weaver et al., 2002). In the current study, IL-6 of course was not detectable in IL- $6^{-1-}$ mice before or after LPS injection. However, it is noteworthy that plasma IL- $1 \beta$ and TNF $\alpha$ were increased similarly in IL- $6^{-/-}$and IL- $6^{+/+}$mice after injection of LPS. This was surprising because IL- $1 \beta$ induces marked sickness behavior when injected peripherally (Segretti et al., 1997). Although sickness behavior was not quantified in the current study, casual observations indicated that both $\mathrm{IL}-6^{-/-}$and $\mathrm{IL}-6^{+/+}$ mice were made ill by LPS. This observation is supported by a similar reduction in swim speed for both strains after LPS injection. Therefore, these data suggest that high circulating levels of IL- $1 \beta$ and TNF $\alpha$ are associated with the sickness behavior syndrome, but are not sufficient to disrupt working memory when IL-6 is not present.

Cytokines that are produced in the periphery activate humoral and neural communication pathways (Buttini and Boddeke, 1995; Quan et al., 1998; Maier et al., 1998; Hansen et al., 2000; Rivest, 2003) that induce glial cells in discrete brain regions to produce the same inflammatory cytokines. Therefore, if IL-6 deficiency influenced the responsiveness of glia in brain areas that regulate cognitive behavior to signals from the peripheral innate immune system (i.e., high plasma levels of IL- $1 \beta$ and TNF $\alpha$ ), this might help explain why IL- $6^{-1-}$ mice did not show deficits in working memory. We measured steady-state levels of inflammatory cytokine mRNAs in hippocampal neuronal cell layers that were separated from surrounding hippocampal tissue by LCM. Although glial cells comprise only $10 \%$ of the hippocampal neuronal layer, this strategy was used to provide a better view of what transpires in an important area of the hippocampus when the 
peripheral innate immune system was activated by LPS in the presence or absence of IL-6. Most studies have examined inflammatory cytokine mRNAs in the entire hippocampal formation after manual dissection, thus combining neurons, glia, and white matter from various regions. In the current study, IL-1 $\beta$, IL-6, and TNF $\alpha$ mRNAs were increased in hippocampal tissue in LPStreated IL- $6^{+/+}$mice. This is consistent with previous findings (Quan et al., 1998; Hansen et al., 2000; Berg et al., 2005). In contrast, the LPS-induced upregulation of IL- $1 \beta$ and TNF $\alpha$ mRNA expression was markedly diminished or prevented altogether in IL- $6^{-1-}$ mice. The pattern of results in this study correspond with a previous report in which IL- $6^{-1-}$ mice administered LPS intracerebroventricularly showed increased circulating levels of TNF $\alpha$, but central levels of TNF $\alpha$ were not increased (Di Santo et al., 1997). In response to LPS, IL- $6^{-/-}$mice also experience less non-REM sleep (Morrow and Opp, 2005) and less severe depression in social behavior (Bluthé et al., 2000) than wild-type controls. Additionally, Kozak et al. (1997) reported that IL- $6^{-1-}$ mice were resistant to behavioral deficits caused by a turpentine-induced abscess or influenza infection. These results demonstrate that IL- 6 plays an important role in the coordination of sickness behaviors after a number of different immune stimuli and that its role is not limited to LPS-associated phenomena.

Because in the current study high circulating levels of inflammatory cytokines were not sufficient to induce inflammatory cytokine production in the hippocampus and induce deficits in working memory in IL- $6^{-/-}$mice, we also explored whether IL-6 deficiency might interfere with the vagal afferent pathway that is responsive to peripheral LPS. Neurons in the NTS receive input from vagal afferents and project to brain areas mediating sickness behavior, including the hippocampus (Rutecki, 1990). In rats, subdiaphragmatic vagotomy attenuated the upregulation of IL- $1 \beta$ in the hippocampus and alleviated behavioral depression after peripheral injection of LPS (Laye et al., 1995). Therefore, if IL-6 deficiency blunted the vagal afferent pathway, it might explain why IL- $6^{-1-}$ mice were refractory to peripheral LPS. However, in the current study, c-Fos immunoreactivity in the NTS was increased similarly in IL- $6^{+/+}$and IL- $6^{-/-}$mice after LPS injection. This result is consistent with that of Vallieres and Rivest (1999), who also showed a similar pattern of c-Fos activation in the NTS of IL-6-deficient mice after a lower dose of LPS.

Because the humoral and neural immune-to-brain communication pathways investigated herein, appear to be independent of IL-6, we interpret our results to suggest that in the absence of IL-6 the central cytokine compartment is less responsive to signals from the peripheral innate immune system. In support of this hypothesis, the response of hippocampal glial cells to neurotoxic lesions induced by kainic acid (Penkowa et al., 2001) or MPTP (methyl-4-phenyl-1,2,3,6-tetrahydropyridine) (Cardenas and Bolin, 2003) was reduced in IL-6-deficient mice. Together, these data suggest that IL- 6 facilitates activation of glial cells and supports inflammatory processes that regulate behavioral/ physiological responses to injury and immunological insult. Therefore, IL-6 may represent a viable therapeutic target to treat behavioral/neurobiological dysfunctions associated with neuroinflammation.

\section{References}

Arai K, Matsuki N, Ikegaya Y, Nishiyama N (2001) Deterioration of spatial learning performances in lipopolysaccharide-treated mice. Jpn J Pharmacol 87:195-201.

Aubert A, Vega C, Dantzer R, Goodall G (1995) Pyrogens specifically dis- rupt the acquisition of a task involving cognitive processing in the rat. Brain Behav Immun 9:129-148.

Balschun D, Wetzel W, del Rey A, Pitossi F, Schneider H, Zuschratter W, Besedovsky HO (2004) Interleukin-6: a cytokine to forget. FASEB J $18: 1788-1790$.

Barrientos RM, Higgins EA, Sprunger DB, Watkins LR, Rudy JW, Maier SF (2002) Memory for context is impaired by a post context exposure injection of interleukin-1 beta into dorsal hippocampus. Behav Brain Res 134:291-298.

Barrientos RM, Higgins EA, Biedenkapp JC, Sprunger DB, Wright-Hardesty KJ, Watkins LR, Rudy JW, Maier SF (2006) Peripheral infection and aging interact to impair hippocampal memory consolidation. Neurobiol Aging 27:723-732.

Berg BM, Godbout JP, Chen J, Kelley KW, Johnson RW (2005) alphaTocopherol and selenium facilitate recovery from lipopolysaccharideinduced sickness in aged mice. J Nutr 135:1157-1163.

Blalock J (1994) The syntax of immune-neuroendocrine communication. Immunol Today, 15:504-511.

Bluthé RM, Michaud B, Poli V, Dantzer R (2000) Role of IL-6 in cytokineinduced sickness behavior: a study IL-6 deficient mice. Physiol Behav 70:367-373.

Braida D, Sacerdote P, Panerai AE, Bianchi M, Aloisi AM, Iosuè S, Sala M (2004) Cognitive function in young and adult IL (interleukin)-6 deficient mice. Behav Brain Res 31:423-429.

Brebner K, Hayley S, Sacharko R, Merali Z, Anisman H (2000) Synergistic effects of interleukin- $1 \beta$, interleukin-6, and tumor necrosis factor-alpha: central monoamine, corticosterone, and behavioral variations. Neuropsychopharmacology 22:566-580.

Butler MP, O'Connor JJ, Moynagh PN (2004) Dissection of tumor-necrosis factor- $\alpha$ inhibition of long-term potentiation (LTP) reveals a p38 mitogen-activated protein kinase-dependent mechanism which maps to early- but not late-phase LTP. Neuroscience 124:319-326.

Buttini M, Boddeke H (1995) Peripheral lipopolysaccharide stimulation induces interleukin- $1 \beta$ messenger RNA in rat brain glial cells. Neuroscience 65:523-530.

Cardenas H, Bolin LM (2003) Compromised reactive microgliosis in MPTP-lesioned IL-6 KO mice. Brain Res 985:89-97.

Cohen O, Reichenberg A, Perry C, Ginzberg D, Pollmacher T, Soreq H, Yirmiya R (2003) Endotoxin-induced changes in human working and declarative memory associate with cleavage of plasma "readthrough" acetylcholinesterase. J Mol Neurosci 21:199-212.

Curran BP, O'Connor JJ (2003) The inhibition of long-term potentiation in the rat dentate gyrus by pro-inflammatory cytokines is attenuated in the presence of nicotine. Neurosci Lett 344:103-106.

Dantzer R (2004) Cytokine-induced sickness behaviour: a neuroimmune response to activation of innate immunity. Eur J Pharmacol 500:399-411.

Di Santo E, Alonzi T, Poli V, Fattori E, Toniatti C, Sironi M, RicciardiCastagnoli P, Ghezzi P (1997) Differential effects of IL-6 on systemic and central production of TNF: a study with IL-6-deficient mice. Cytokine 9:300-306.

Gadient RA, Otten U (1994) Identification of interleukin-6 (IL-6)expressing neurons in the cerebellum and hippocampus of normal adult rats. Neurosci Lett 182:243-246.

Hansen MK, Nguyen KT, Goehler LE, Gaykema RP, Fleshner M, Maier SF, Watkins LR (2000) Effects of vagotomy on lipopolysaccharide-induced brain interleukin-1beta protein in rats. Auton Neurosci 85:119-226.

Haour F, Jafarian-Tehrani M, Gabellec MM, Crumeyrolle-Arias M, Hu Y, Wick G, Ternynck T (1998) Interleukin-1 receptor defect in autoimmune NZB mouse brain. Ann NY Acad Sci 840:755-761.

Johnston M, Wakeling A, Graham N, Stokes F (1987) Cognitive impairment, emotional disorder and length of stay of elderly patients in a district general hospital. Br J Med Psychol 60:133-139.

Kelley K, Bluthé R, Dantzer R, Zhou J, Shen W, Johnson R, Broussard SR (2003) Cytokine induced sickness behavior. Brain Behav Immun 17:S112-S118.

Konsman JP, Parnet P, Dantzer R (2002) Cytokine-induced sickness behavior: mechanisms and implications. Trends Neurosci 25:154-159.

Kopf M, Baumann H, Freer G, Freudenberg M, Lamers M, Kishimoto T, Zinkernagel R, Bluethmann H, Kohler G (1994) Impaired immune and acute-phase responses in interleukin-6-deficient mice. Nature 368:339-342. 
Kozak W, Poli V, Soszynski D, Conn CA, Leon LR, Kluger MJ (1997) Sickness behavior in mice deficient in interleukin- 6 during turpentine abscess and influenza pneumonitis. Am J Physiol R621-R630.

Laye S, Bluthe RM, Kent S, Combe C, Medina C, Parnet P, Kelley K, Dantzer R (1995) Subdiaphragmatic vagotomy blocks induction of IL-1 beta mRNA in mice brain in response to peripheral LPS. Am J Physiol 268:R1327-R1331.

Loddick S, Liu C, Takao T, Hashimoto K, De Souza E (1998) Interleukin-1 receptors: cloning studies and role in central nervous system disorders. Brain Res Rev 26:306-319.

Maier S, Goehler L, Fleshner M, Watkins L (1998) The role of the vagus nerve in cytokine-to-brain communication. Ann NY Acad Sci 840:289-300

Morris R (1984) Developments of a water-maze procedure for studying spatial learning in the rat. J Neurosci Methods 11:47-60.

Morrow JD, Opp MR (2005) Diurnal variation of lipopolysaccharideinduced alterations in sleep and body temperature of interleukin-6deficient mice. Brain Behav Immun 19:40-51.

Parnet P, Kelley K, Bluthé R, Dantzer R (2002) Expression and regulation of interleukin-1 receptors in the brain. Role in cytokines-induced sickness behavior. J Neuroimmunol 125:5-14.

Penkowa M, Molinero A, Carrasco J, Hidalgo J (2001) Interleukin-6 deficiency reduces the brain inflammatory response and increases oxidative stress and neurodegeneration after kainic acid-induced seizures. Neuroscience 102:805-818.

Pickering M, Cumiskey D, O'Connor JJ (2005) Actions of TNF-alpha on glutamatergic synaptic transmission in the central nervous system. Exp Physiol 90:663-670.

Pugh CR, Kumagawa K, Fleshner M, Watkins LR, Maier SF, Rudy JW (1998) Selective effects of peripheral lipopolysaccharide administration on contextual and auditory-cue fear conditioning. Brain Behav Immun 12:212-229.

Pugh CR, Fleshner M, Watkins L, Maier SF, Rudy J (2001) The immune system and memory consolidation: a role for the cytokine IL-1beta. Neurosci Biobehav Rev 25:29-41.

Quan N, Whitesides M, Herkenham M (1998) Time course and localization patterns of interleukin-1 $\beta$ messenger RNA expression in brain and pituitary after peripheral administration of lipopolysaccharide. Neuroscience 83:281-293.

Reichenberg A, Yirmiya R, Schuld A, Kraus T, Haack M, Morag A, Pollmacher T (2001) Cytokine-associated emotional and cognitive disturbances in humans. Arch Gen Psychiatry 58:445-452.

Rivest S (2003) Molecular insights on the cerebral innate immune system. Brain Behav Immun 17:13-19.
Rutecki P (1990) Anatomical, physiological, and theoretical basis for the antiepileptic effect of vagus nerve stimulation. Epilepsia 31:S1-S6.

Schneider H, Pitossi F, Balschun D, Wagner A, del Rey A, Besedovsky HO (1998) A neuromodulatory role of interleukin-1beta in the hippocampus. Proc Natl Acad Sci USA 95:7778-7783.

Segretti J, Gheusi G, Dantzer R, Kelley KW, Johnson RW (1997) Defect in interleukin-1beta secretion prevents sickness behavior in $\mathrm{C} 3 \mathrm{H} / \mathrm{HeJ}$ mice. Physiol Behav 61:873-878.

Shaw KN, Commins S, O’Mara SM (2001) Lipopolysaccharide causes deficits in spatial learning in the watermaze but not in BDNF expression in the rat dentate gyrus. Behav Brain Res 124:47-54.

Sparkman NL, Kohman RA, Garcia AK, Boehm GW (2005a) Peripheral lipopolysaccharide administration impairs two-way active avoidance conditioning in C57BL/6J mice. Physiol Behav 85:278-288.

Sparkman NL, Kohman RA, Scott VJ, Boehm GW (2005b) Bacterial endotoxin-induced behavioral alterations in two variations of the Morris water maze. Physiol Behav 86:244-251.

Squire L (1992) Memory and the hippocampus: a synthesis from findings with rats, monkeys, and humans. Psych Rev 99:195-231.

Takao T, Culp S, Newton R, De Souza E (1992) Type I interleukin-1 receptors in the mouse brain-endocrine-immune axis labeled with $\left[{ }^{125} \mathrm{I}\right] \mathrm{re}$ combinant human interleukin-1 receptor antagonist. J Neuroimmunol 41:51-60.

Tancredi V, D’Antuono M, Cafe C, Giovedi S, Bue MC, D'Arcangelo G Onofri F, Benfenati F (2000) The inhibitory effects of interleukin-6 on synaptic plasticity in the rat hippocampus are associated with an inhibition of mitogen-activated protein kinase ERK. J Neurochem 75:634-643.

Vallieres L, Rivest S (1999) Interleukin-6 is a needed proinflammatory cytokine in the prolonged neural activity and transcriptional activation of corticotropin-releasing factor during endotoxemia. Endocrinology 140:3890-3903.

Vereker E, O'Donnell E, Lynch MA (2000) The inhibitory effect of interleukin- $1 \beta$ on long-term potentiation is coupled with increased activity of stress-activated protein kinases. J Neurosci 20:6811-6819.

Weaver JD, Haung M, Albert M, Harris T, Rowe JW, Seeman TE (2002) Interleukin-6 and risk of cognitive decline: MacArthur studies of success aging. Neurology 59:371-378.

Wofford JL, Loehr LR, Schwartz E (1996) Acute cognitive impairment in elderly ED patients: etiologies and outcomes. Am J Emerg Med 14:649-653.

Yirmiya R, Winocur G, Goshen I (2002) Brain interleukin-1 is involved in spatial memory and passive avoidance conditioning. Neurobiol Learn Mem 78:379-389. 